\title{
Flora Polínica da Reserva do Parque Estadual das Fontes do Ipiranga (São Paulo, Brasil)
}

\author{
Família: 61-Cucurbitaceae
}

Maria Amélia Vitorino da Cruz-Barros ${ }^{1,2}$, Angela Maria da Silva Corrêa ${ }^{1}$ e Fernanda Alves de Amorim ${ }^{1}$

Recebido: 15.09.2011; aceito: 12.01.2012

\begin{abstract}
Pollen flora of "Reserva do Parque Estadual das Fontes do Ipiranga" (São Paulo, Brazil). Family: 61 - Cucurbitaceae). Pollen grains of seven genera and 11 taxa of Cucurbitaceae (Anisosperma passiflora (Vell.) A. Silva Manso, Cayaponia cabocla (Vell.) Mart., C. martiana (Cogn.) Cogn., C. pilosa (Vell.) Cogn., C. villosissima Cogn., Echinocystis racemosa (Steud.) Mart. Crov., Melothria campestre Naudin., M. cucumis Vell. var. cucumis, Sicydium gracile Cogn., Sicyos polyacanthos Cogn., and Wilbrandia verticillata (Vell.) Cogn, ocurring in the "Reserva do Parque Estadual das Fontes do Ipiranga", were studied. Descriptions and illustrations are presented for all studied species.
\end{abstract}

Key words: Cucurbitaceae, pollen flora, pollen grains

RESUMO - (Flora Polínica da Reserva do Parque Estadual das Fontes do Ipiranga (São Paulo, Brasil). Família: 61 - Cucurbitaceae). Neste trabalho foram estudados os grãos de pólen de sete gêneros e 11 táxons de Cucurbitaceae (Anisosperma passiflora (Vell.) A. Silva Manso, Cayaponia cabocla (Vell.) Mart., C. martiana (Cogn.) Cogn., C. pilosa (Vell.) Cogn., C. villosissima Cogn., Echinocystis racemosa (Steud.) Mart. Crov., Melothria campestre Naudin., M. cucumis Vell. var. cucumis, Sicydium gracile Cogn., Sicyos polyacanthos Cogn. e Wilbrandia verticillata (Vell.) Cogn.), ocorrentes na "Reserva do Parque Estadual das Fontes do Ipiranga". São apresentadas descrições e ilustrações para todas espécies estudadas. Palavras-chave: Cucurbitaceae, flora polínica, grãos de pólen

\section{Introdução}

O presente trabalho faz parte do projeto elaborado por Melhem et al. (1984), que visa realizar o levantamento polínico das famílias que ocorrem na Reserva do Parque Estadual das Fontes do Ipiranga (PEFI), com o objetivo de complementar os estudos taxonômicos realizados na mesma área, segundo planejamento apresentado por Melhem et al. (1981) e finalizado em Nakajima et al. (2001). O formato atual da Flora polínica do PEFI segue Cruz-Barros \& Souza (2005).

De acordo com Klein (2001), a família Cucurbitaceae está representada nesta Reserva por sete gêneros e 12 espécies: Anisosperma A. Silva Manso (A. passiflora (Vell.) A. Silva Manso), Cayaponia A. Silva Manso (C. cabocla (Vell.) Mart., C. martiana (Cogn.) Cogn., C. pilosa (Vell.) Cogn., C. villosissima
Cogn.), Echinocystis Torr. \& Gray (E. racemosa (Steud.) Mart. Crov.), Melothria L. (M. campestris Naudin. H. Shaef. \& S.S. Renner, M. cucumis Vell. var. cucumis), Sicydium Schltdl. (S. gracile Cogn.), Sicyos L. (S. polyacanthos Cogn.) e Wilbrandia J. Silva Manso ( $W$. verticillata (Vell.) Cogn.), além de Cayaponia sp.

Com base em uma nova classificação da família Cucurbitaceae proposta por Shaefer \& Renner (2011), Melancium campestre Naudin passou a ser tratada como Melothria campestris (Naudin) H. Schaef. \& S.S. Renner, mudança essa que está sendo aceita no presente trabalho.

Segundo os dados disponíveis na literatura (Erdtman 1952, Campos 1962, Melhem 1966, Roubik \& Moreno 1991, Lira et al. 1998, García et al. 2003, Melhem et al. 2003, Lira 2004, Barth et al. 2005, Van der Ham \& Pruesapan 2006, Perveen \& Qaiser 2008)

1. Instituto de Botânica, Caixa Postal 68041, 04045-972 São Paulo, SP, Brasil

2. Autor para correspondência: mcruzbarros@gmail.com 
a família Cucurbitaceae apresenta grãos de pólen em mônades ou tétrades; inaperturados, 3-colporados, 3-porados, polizonoporados, polizonocolpados, pantocolpados a pantoporados; exina psilada, foveolada, espinhosa, espiculada, reticulada, reticulado-rugulada, estriada, estriado-reticulada, verrugado-escabrada.

\section{Material e métodos}

Os botões florais foram obtidos a partir de material herborizado depositado no Herbário Científico do Estado "Maria Eneyda P. Kauffmann Fidalgo" (SP).

Alguns espécimes coletados na Reserva citados por Klein (2001) não foram incluídos no presente estudo por estarem em fruto, ou com material polínico amassado e insuficiente para a realização de medidas, ou ainda exsicatas não localizadas, por isso estudou-se apenas os materiais da Reserva que estavam em boas condições para análise polínica. Os materiais J.V. Godoi 317 (SP), O. Handro 428 (SP) e F.C.Hoehne s.n. (SP28839), nativos na Reserva, citados no trabalho de Klein (2001) como Cayaponia sp. e posteriormente identificados como Cayaponia membranacea Gomes-Klein, não foram estudados devido à falta de botões florais nas exsicatas dos principais herbários consultados.

Os grãos de pólen foram preparados segundo o método de acetólise (Erdtman 1960), acrescido das modificações citadas em Melhem et al. (2003). As ilustrações foram feitas em microscopia óptica com grãos de pólen acetolisados e fotografados digitalmente, utilizando-se fotomicroscópio Olympus BX 50 acoplado a uma câmara de vídeo e microcomputador (PC) e o programa Image-Pro Plus versão 3 para Windows. As espécies Cayaponia martiana e Echinocystes racemosa foram também, fotomicrografadas em um microscópio eletrônico de varredura de varredura (MEV), Philips XL, série XL $20 \mathrm{~S} / \mathrm{W}$, ver. 5.21, a fim de elucidar dúvidas quanto à ornamentação da exina.

A terminologia adotada está de acordo com Barth \& Melhem (1988) e Punt et al. (2007).

As lâminas com o material polínico encontram-se depositadas na palinoteca do Núcleo de Pesquisa em Palinologia do Instituto de Botânica.

\section{Resultados e Discussão}

\author{
Anisosperma A. Silva Manso
}

1. Anisosperma passiflora (Vell.) A. Silva Manso Figuras 1-4
Forma: prolato-esferoidal (raro oblato-esferoidal), âmbito subcircular.

Abertura: 3 cólporos, colpos longos, largos, operculados; endoabertura lolongada, com margem.

Exina: estriada, sexina mais espessa que a nexina.

Medidas $(\mu \mathrm{m})$ : F.C. Hoehne s.n., SP28204: $\mathrm{P}=29,2 \pm 0,2 ; \mathrm{E}=27,3 \pm 0,2 ;$ diâm. equatorial em vista polar $=26,8 \pm 0,2$; cólporo compr.ca. 25,2 , larg. ca. 3,7; endoabertura compr. ca. 4,6, larg. ca. 3,4; exina ca. 1,8 , sexina ca. 1,0 e nexina ca. 0,8 .

F. Barros 1958: $\mathrm{P}=28,4 ; \mathrm{E}=27,6$; diâm. equatorial em vista polar $=27,5$.

A. Custodio Filho 13: $\mathrm{P}=30,4 ; \mathrm{E}=29,2$; diâm. equatorial em vista polar $=28,3$.

T.P.M. Fino et al. 9: $\mathrm{P}=29,5 ; \mathrm{E}=29,4$; diâmetro equatorial em vista polar $=29,6$.

J.V. Godoi 324: $\mathrm{P}=31,4 ; \mathrm{E}=28,9$; diâm. equatorial em vista polar $=29,1$.

J.V. Godoi 337: $\mathrm{P}=28,3 ; \mathrm{E}=28,1$; diâm. equatorial em vista polar $=27,4$.

M. Kirizawa 176: $\mathrm{P}=31,9 ; \mathrm{E}=28,7$; diâm. equatorial em vista polar $=29,2$.

M.M.R.F. Melo et al. 67: $\mathrm{P}=29,4 ; \mathrm{E}=30,0$; diâm. equatorial em vista polar $=29,4$.

Observações: Os espécimes da Reserva citados por Klein (2001), S.A.C. Chiea 97 (SP), J.V. Godoi 346 (SP) e N.A. Rosa et al. 3686 (SP), não foram estudados por escassez de material polínico possuírem apenas por frutos.

Material estudado: 5-XI-1931, F.C. Hoehne s.n. (SP28204); 23-XI-1990, F. Barros 1958 (SP); 15-III-1993, J.V. Godoi 324 (SP); 23-III-1993, J.V. Godoi 337 (SP); 12-I-1983, T.P.M. Fino et al. 9 (SP); 16-II-1988, M. Kirizawa 176 (SP); 27-II-1978, M.M.R.F. Melo et al. 67 (SP); 8-II-1979, A. Custodio Filho 13 (SP).

\section{Cayaponia A. Silva Manso}

Grãos de pólen variando de oblato-esferoidais a prolato-esferoidais; âmbito circular; 3-4-5-6-porados, poros sem margem, operculados; sexina intectada, espinhosa, espinhos grandes pontiagudos intercalados por inúmeros espículos pontiagudos ou de ápice arredondados. Sob MEV os opérculos apresentam a mesma ornamentação que a região não apertural.

1. Cayaponia cabocla (Vell.) Mart.

Figuras 5-7

Forma: oblato-esferoidal.

Aberturas: 3 poros. 

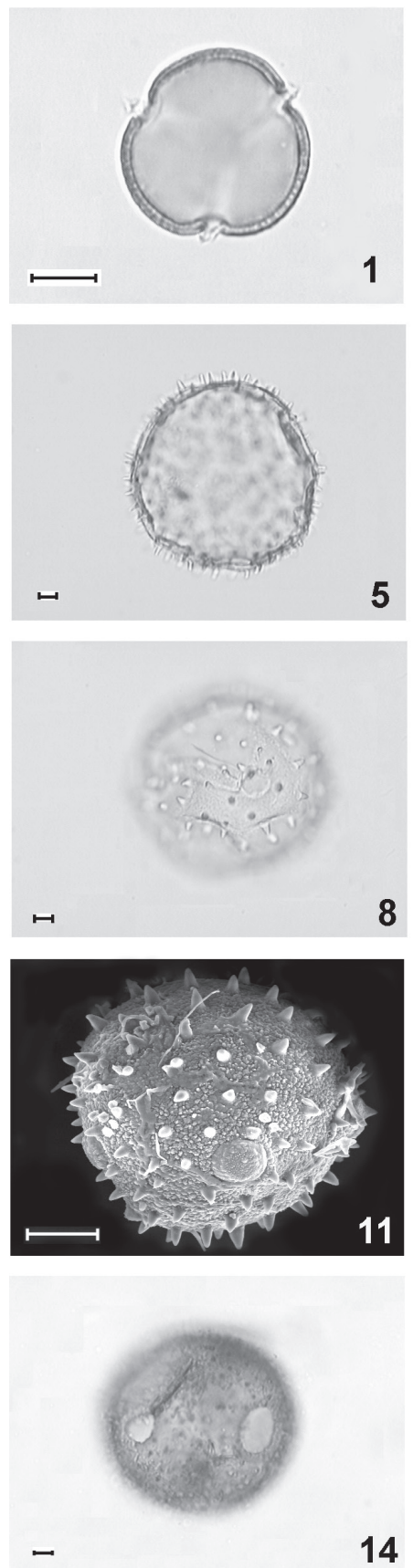

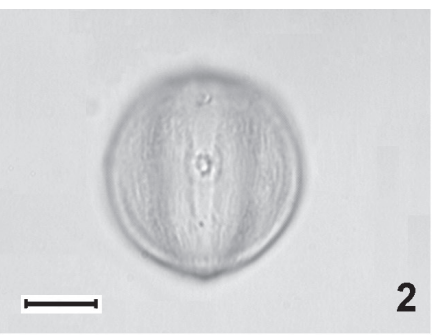

2
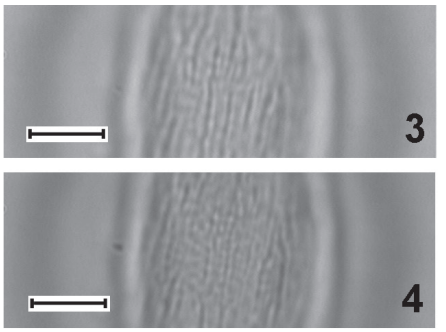

6
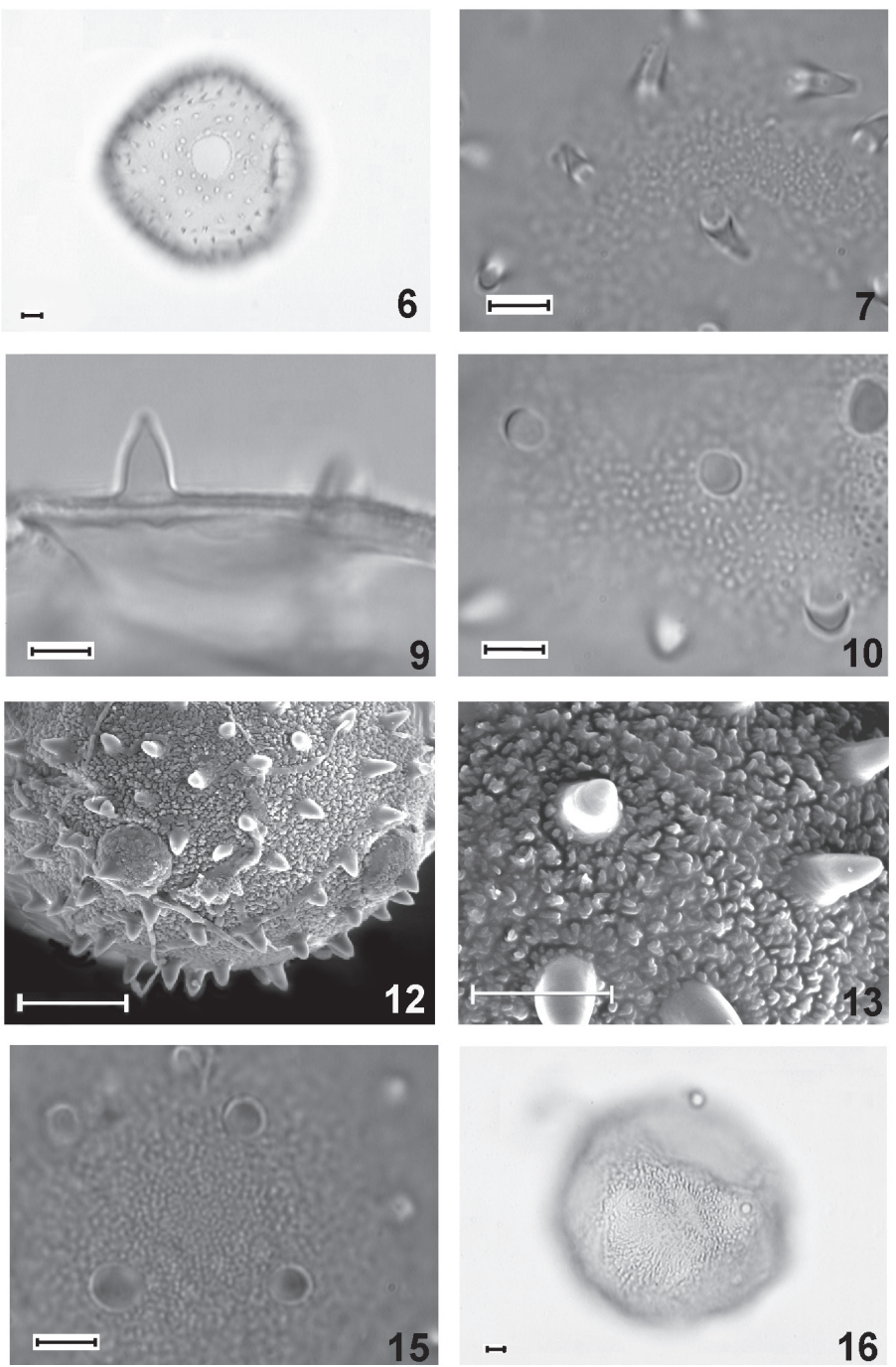

Figuras 1-16. Fotomicrografias e eletromicrografias (MEV) dos grãos de pólen de Cucurbitaceae. 1-4. Anisosperma passiflora (Vell.) A. Silva Manso. 1. Vista polar. 2. Vista equatorial mostrando o cólporo. 3-4. Análise de L.O. 5-7. Cayaponia cabocla (Vell.) Mart. 5. Vista polar. 6. Vista equatorial mostrando o poro. 7. Detalhe da ornamentação. 8-10. Cayaponia martiana (Cogn.) Cogn. 8. Vista equatorial. 9. Corte óptico. 10. Detalhe da ornamentação. 11-13. Eletromicrografias (MEV) de Cayaponia pilosa (Vell.) Cogn. 11. Vista equatorial. 12. Detalhe do poro mostrando o espinho sobre este. 13. Detalhe da ornamentação. 14-15. Cayaponia villosisisima Cogn. 14 Vista equatorial mostrando os poros. 15. Detalhe da ornamentação. 16. Echinocystis racemosa (Steud.) Mart., vista geral do grão de pólen. Barras de escala $=10 \mu \mathrm{m}(1,2,5,6,8,13,14,16) ; 5 \mu \mathrm{m}(3,4,7,9,10,15) ; 20 \mu \mathrm{m}(11-12)$.

Figure 1-16. Photomicrographs and scanning electron micrographs (SEM) of pollen grains of Cucurbitaceae. 1-4. Anisosperma passiflora (Vell.) A. Silva Manso.1. Polar view. 2. Equatorial view showing the colporus. 3-4. L.O. analysis. 5-7. Cayaponia cabocla (Vell.) Mart. 5. Polar view. 6. Equatorial view showing the porus. 7. Ornamentation. 8-10. Cayaponia martiana (Cogn.) Cogn. 8. Equatorial view showing the porus. 9. Optical section. 10. Ornamentation. 11-13. Scanning Electron micrographs (SEM) Cayaponia pilosa (Vell.) Cogn. 11. Equatorial view. 12. Detail of the spine over the porus. 13. Detail of ornamentation. 14-15. Cayaponia villosisisima Cogn. 14. Equatorial view showing the porus. 15. Ornamentation. 16. Echinocystis racemosa (Steud.) Mart. General view of pollen grains. Bars $=10 \mu \mathrm{m}(1$, $2,5,6,8,13,14,16) ; 5 \mu \mathrm{m}(3,4,7,9,10,15) ; 20 \mu \mathrm{m}(11-12)$. 
Medidas $(\mu \mathrm{m}): \mathrm{P}=112,3 \pm 1,2 ; \mathrm{E}=115,9 \pm 1,0$; diam. equatorial em vista polar $=112,0 \pm 0,9$; poro diâm. ca. 20,0; exina ca. 9,0, sexina com espinho ca. 7,7, nexina ca. 1,3 e espinho ca. $=6,2$.

Observações: Barth et al. (2005), estudaram trinta espécies de Cayaponia ocorrentes no Brasil, enquadrando-os em cinco tipos polínicos principais e vários subtipos levando em consideração o tamanho dos grãos de pólen e o número de aberturas respectivamente. As autoras enquadraram os grãos de pólen C. cabocla dentro do tipo polínico 2, subtipo 1, com grãos de pólen muito grandes e com 3 poros. Os resultados aqui obtidos para C. cabocla corroboraram os de Barth et al. (2005).

Material estudado: 9-II-1918, F.C. Hoehne s.n. (SP2603).

\section{Cayaponia martiana (Cogn.) Cogn.}

Figuras 8-10

Forma: oblato-esferoidal.

Aberturas: 4-5-6 poros, zonoporados.

Medidas $(\mu \mathrm{m}): \mathrm{P}=100,2 \pm 1,6 ; \mathrm{E}=105,3 \pm 1,7$, diâm. equatorial em vista polar $=121,2$; poro diâm. ca. 13,0; exina ca. 8,8, sexina com espinho ca. 7,3, nexina ca. 1,7 e espinho ca. $=6,3$.

Observações: Os materiais da Reserva, J.A. Corrêa 96 (SP), W. Hoehne 6205 (SP), M. Kuhlmann 3545 a e C.B. Toledo et al. 72 (SP) citados por Klein (2001), não foram estudados por possuírem somente frutos. Ao observarem os grãos de pólen dessa espécie, Barth et al. (2005), enquadraram-os dentro do tipo polínico 1 , subtipo 2 por serem grandes e apresentarem aberturas 4-6-poradas. Com relação ao tamanho, os grãos de pólen descritos pelas autoras divergem do presente estudo por serem menores que os do espécime aqui analisado.

Material estudado: 15-III-1993, J.V. Godoi 319 (SP).

\section{Cayaponia pilosa (Vell.) Cogn.}

Figuras 11-13

Forma: oblato-esferoidal.

Aberturas: 3-4 poros.

Medidas $(\mu \mathrm{m})$ : O. Handro s.n., SP39418: $\mathrm{P}=95,7 \pm 2,9 ; \mathrm{E}=100,0 \pm 2,5 ;$ diâm. equatorial em vista polar $=97,6 \pm 3,0$; poro diâm. ca. 16,0 ; exina ca. 10,3 , sexina com espinho ca. 9,0 , nexina ca. $=1,2$ e espinho ca. 8,2.

F.C. Hoehne 109: $\mathrm{P}=105,0 ; \mathrm{E}=108,8$; diâm. equatorial em vista polar $=107,5$
Observações: Esta espécie foi estudada por Melhem et al. (2003) e por Barth et al. (2005). Os resultados apresentados por essas autoras são semelhantes aos espécimes aqui observados. Barth et al. (2005) enquadraram os grãos de pólen de C. pilosa no tipo polínico 1, subtipo 1, por serem grandes e possuírem 3-4 poros.

Material estudado: 20-I-1938, O. Handro s.n. (SP39418); 1-VI-1918, F.C. Hoehne 109 (SP).

\section{Cayaponia villosissima Cogn.}

Figuras 14-15

Forma: prolato-esferoidal a oblato-esferoidal.

Aberturas: $4-5$ poros.

Medidas $(\mu \mathrm{m})$ : M. Kuhlmann 3125 : $\mathrm{P}=120,6 \pm 1,1 ; \mathrm{E}=122,1 \pm 1,4 ;$ diâm. equatorial em vista polar $=120,1 \pm 1,9$; poro diâm. ca. 13,0 ; exina ca. 6,7 , sexina com espinho ca. 4,8 , nexina ca. 1,6 e espinho ca. 4,1.

M.S.F. Silvestre 220: $\mathrm{P}=118,4 ; \mathrm{E}=115,6$; diâm. equatorial em vista polar $=116,2$.

Observações: Os materiais da Reserva citados por Klein (2001), W. Bockermann s.n. (SP175991), R. Farias 31 (SP), J.V. Godoi 328 (SP), O. Handro 2189 (SP), F.C. Hoehne s.n. (SP31776), M.M.R.F. Melo et al. (SP) e M.S.F. Silvestre 237, não foram estudados por possuírem somente frutos ou por escassez de material polínico. Ao analisar um espécime de C. villosissima, Barth et al. (2005) enquadraram os grãos dessa espécie no tipo polínico 2 por serem muito grandes e no subtipo 1 por possuírem aberturas 4-poradas; já no presente estudo, os dois espécimes aqui observados apresentaram aberturas 4-5 poradas, enquadrando-se dessa forma, dentro do tipo polínico apresentado por Barth et al. (2005).

Material estudado: 17-XII-1945, M. Kuhlmann 3125 (SP), 28-XI-1979, M.S.F. Silvestre 220 (SP).

\section{Echinocystis Torr. \& Gray}

1. Echinocystis racemosa (Steud.) Mart. Crov. Figuras 16-18

Forma: apolar, esférico.

Aberturas: pantocolpadas, colpos longos, largos, de contorno irregulares e de difícil visualização.

Exina: tectado-verrugado, verrugas de tamanhos diferentes e com perfurações esparsas no teto.

Medidas $(\mu \mathrm{m})$ : Diâmetro $=129,7 \pm 0,5$; colpo compr. ca. 29,7, larg. ca. 8,0; exina ca. 4,7, sexina ca.3,1 e nexina ca.1,7. 
Observações: Segundo Klein (2001) esta espécie é frequentemente tratada como Echinopepon racemosus (Steud.) C. Jeffrey, tendo sido estudada sob este nome por García et al. (2003) que descreveu seus grãos de pólen como pantocolpados, com exina microrreticulado-espiculada e com diâmetros variando de 108 a $130 \mu \mathrm{m}$. No presente estudo observou-se que, sob MEV, a exina dessa espécie difere do referido autor por ser verrugada com perfurações esparsas.

Material estudado: 9-III-1976, M. Sakane 437 (SP).

\section{Melothria L.}

Grãos de pólen oblato-esferoidais; âmbito circular a subtriangular; 3-colporados, cólporos longos, largos, com margem fina, operculados, endoaberturas lalongadas, com extremidades arredondadas e constritas na região mediana, ou de difícil visualização; exina reticulada, sexina mais espessa que a nexina.

1. Melothria campestris (Naudin) H. Schaef. \& S.S. Renner

Figuras 19-22

Forma: âmbito circular.

Aberturas: endoabertura lalongada de difícil visualização, às vezes, parece ser lolongada (figura 21) devido a ornamentação da exina, que recobre parte da endoabertura, deixando um orifício na região de intersecção com o colpo.

Medidas $(\mu \mathrm{m}): \mathrm{P}=52,0 \pm 0,3 ; \mathrm{E}=53,3 \pm$ 0,2 ; diâm. equatorial em vista polar $=52,9 \pm 0,3$; cólporo compr. ca. 44,6, larg. ca. 6,4, margem ca. 2,1 ; endoabertura compr. ca. 6,6, larg. ca. 18,2; exina ca. 3,9, sexina ca. 2,7 e nexina ca. 1,0.

Observações: Esta espécie foi estudada por Melhem (1966) sob o nome de Melancium campestre Naudin, apresentando resultados semelhantes aos do presente estudo, entretanto essa autora não mencionou a presença de opérculos, caráter bem visível no presente estudo.

Material estudado: 15-V-1934, F.C. Hoehne s.n. (SP31753)

2. Melothria cucumis Vell. var. cucumis

Figuras 23-26

Forma: âmbito subtriangular

Aberturas: endoabertura lalongada, com extremidades arredondadas e constrita na região mediana.
Medidas $(\mu \mathrm{m})$ : S.L. Jung et al. 300: $\mathrm{P}=52,3 \pm 1,2 ; \mathrm{E}=53,5 \pm 0,2$; diâm. equatorial em vista polar $=52,7 \pm 0,2$; cólporo compr. ca 42,8 , larg. ca. 4,7; endoabertura compr. ca. 5,8, larg. ca. 18,2; exina ca. 3,6, sexina ca. 2,3 e nexina ca. 1,4.

Material estudado: 3-X-1979, S.L. Jung et al. 300 (SP).

Sicydium Schltdl.

\section{Sicydium gracile Cogn.}

Figuras 27-28

Forma: prolato, âmbito subcircular.

Aberturas: 3 cólporos, colpos longos, largos, com margem, operculados apresentando membrana ornamentada, endoaberturas circulares.

Exina: estriada, nexina ligeiramente mais espessa que a sexina.

Medidas $(\mu \mathrm{m}): \mathrm{P}=31,0 \pm 0,5 ; \mathrm{E}=20,7 \pm 0,4 ;$ diâm. equatorial em vista polar $=22,4 \pm 0,4$; cólporo compr. ca. 25,2, larg. ca. 6,1, margem ca. 2,0; endoabertura compr. ca. 3,5, larg. ca. 3,1; exina ca. 1,9, sexina ca. 0,8 e nexina ca. 0,9 .

Observações: Os materiais da Reserva G. Hashimoto 104 (SP) e M.S.F. Silvestre 101 (SP) citados por Klein (2001), não foram estudados, respectivamente, por possuir apenas flor feminina e frutos, dessa forma foi estudado o material Kirizawa et al. 1062 proveniente de outra localidade. Lira et al. (1998), ao estudarem os grãos de pólen de $S$. gracile, obtiveram resultados semelhantes ao espécime aqui analisado.

Material estudado: BRASIL. São Paulo: Mogi das Cruzes, 16-IX-1983, Kirizawa et al. 1062 (SP).

\section{Sicyos L.}

\section{Sicyos polyacanthos Cogn.}

Figuras 29-32

Forma: suboblata, âmbito circular.

Aberturas: 8 colpos, colpos longos e largos.

Exina: espinhosa, espinhos pontiagudos sobre microrreticulos.

Medidas $(\mu \mathrm{m})$ : F.C. Hoehne s.n., SP29295: $\mathrm{P}=61,7 \pm 0,4 ; \mathrm{E}=75,1 \pm 0,5 ;$ diâm. equatorial em vista polar $=74,4 \pm 0,7$; colpo compr. ca. 42,2 , larg. ca. 7,8; exina ca. 6,8 , sexina com espinho ca. $=5,2$, nexina ca. 1,5 e espinho ca. 4,1.

M. Kirizawa \& M.M.R.F. Melo 536: $\mathrm{P}=59,6$; $\mathrm{E}=74,1$; diam. equatorial em vista polar $=75,3$. 

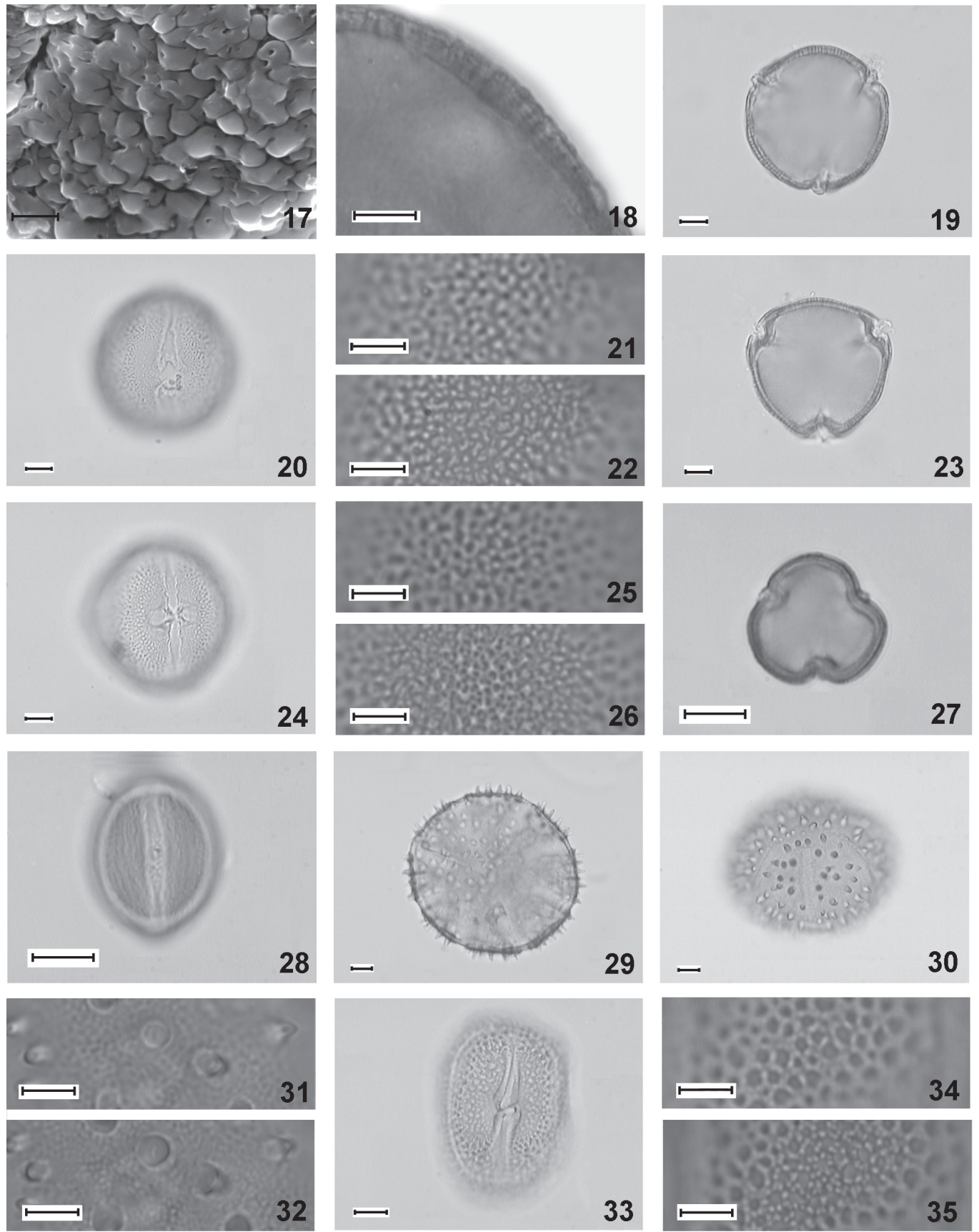

Figuras 17- 35. Fotomicrografias e eletromicrografias (MEV) dos grãos de pólen de Cucurbitaceae. 17-18. Echinocystis racemosa (Steud.) Mart. Crov. 17. Detalhe da ornamentação (MEV). 18. Corte óptico. 19-22. Melothria campestris (Naudin) H. Schaef. \& S.S. Renner. 19. Vista polar. 20. Vista equatorial mostrando o cólporo. 21-22. Análise de L.O. 23-26. Melothria cucumis Vell. var. cucumis. 23. Vista polar. 24. Vista equatorial mostrando o cólporo. 25-26. Análise de L.O. 27-28. Sicydium gracile Cogn. 27. Vista polar. 28. Vista equatorial mostrando o cólporo. 29-32. Sicyos polyacanthos Cogn. 29. Vista polar. 30. Vista equatorial mostrando os colpos. 31-32. Análise de L.O. 33-35. Wilbrandia verticillata (Vell.) Cogn.. 33. Vista equatorial. 34-35. Análise de L.O. Barras de escala $=2 \mu \mathrm{m}(17) ; 5 \mu \mathrm{m}(18,21,22$, $25,26,31,32,34,35) ; 10 \mu \mathrm{m}(19,20,23,24,27,28,29,30,33)$.

Figure 17-35. Photomicrographs and scanning electron micrographs (SEM) of pollen grains of Cucurbitaceae. 17-18. Echinocystis racemosa (Steud.) Mart. Crov. 17. Detail of ornamentation (SEM). 18. Optical section. 19-22. Melothria campestris (Naudin) H. Schaef. \& S.S. Renner. 19. Polar view. 20. Equatorial view showing the colporus. 21-22. L.O. analysis. 23-26. Melothria cucumis Vell. var. cucumis. 23. Polar view. 24. Equatorial view showing the colporus. 25-26. L.O. analysis. 27-28. Sicydium gracile Cogn. 27. Polar view. 28. Equatorial view showing the colporus and ornamentation. 29-32. Sicyos polyacanthos Cogn. 29. Polar view. 30. Equatorial view showing the colpus. 31-32. L.O. analysis. 33-35. Wilbrandia verticillata (Vell.) Cogn. 33. Equatorial view showing the colporus. $34-35$. L.O. analysis. Bars $=2 \mu \mathrm{m}(17) ; 5 \mu \mathrm{m}(18,21,22,25,26,31,32,34,35) ; 10 \mu \mathrm{m}(19,20,23,24,27,28,29,30,33)$. 
Observações: O espécime da Reserva W. Hoehne 5732 (SP) citado por Klein (2001), não foi estudado por escassez de material polínico.

Material estudado: 18-III-1932, F.C. Hoehne s.n. (SP29295), 26-III-1980, M. Kirizawa \& M.M.R.F. Melo 536 (SP).

\section{Wilbrandia J. Silva Manso}

\section{Wilbrandia verticillata (Vell.) Cogn.}

Figuras 33-35

Forma: prolata, âmbito subcircular

Aberturas: 3 cólporos, colpos longos, largos, com margem espessa; endoabertura lalongada, de difícil visualização.

Exina: reticulada, sexina mais espessa que a nexina.

Medidas $(\mu \mathrm{m}): \mathrm{P}=55,5 ; \mathrm{E}=32,0$; diâm. equatorial em vista polar $=52,7$; cólporo compr. ca. 42,3, larg. ca. 4,9, margem ca. 5,0; endoabertura compr. ca. 2,0, larg. ca. 6,6; exina ca. 2,9, sexina ca. 1,7 e nexina ca. 1,2 .

Observações: Os materiais da Reserva R. Farias 22 (SP), A.C. Marufa et al. 69 (SP), não foram estudados por não possuírem material polínico.

Material estudado: 17-XII-1980, F. Barros 594 (SP).

Chave para espécies de Cucurbitaceae do PEFI

1. Grãos de pólen verrugosos ou reticulados

2. Grãos de pólen verrugosos Echinocystis racemosa

2. Grãos de pólen reticulados

3. Colpos sem opérculos; grãos de pólen prolatos

3. Colpos com opérculos; grãos de pólen oblato-esferoidais Wilbrandia verticillata Melothria campestris

1. Grãos de pólen estriados ou espinhosos

4. Grãos de pólen estriados

5. Endoaberturas circulares Sicydium gracile

5. Endoaberturas lolongadas Anisosperma passiflora

4. Grãos de pólen espinhosos

6. Grãos de pólen colpados

6. Grãos de pólen porados Sicyos polyacanthos

7. Poro $\geq 19,0 \mu \mathrm{m}$ Cayaponia pilosa

7. Poro $\leq 17,0 \mu \mathrm{m}$

8. Grãos de pólen 3-porados Cayaponia cabocla

8. Grãos de pólen 4-6-porados Cayaponia martiana Cayaponia villosissima

\section{Literatura citada}

Barth, O.M. \& Melhem, T.S. 1988. Glossário ilustrado de palinologia. Universidade Estadual de Campinas, Campinas.

Barth, O.M., Luz, C.F.P. \& Gomes-Klein, V.L. 2005. Pollen morphology of Brazilian species of Cayaponia Silva Manso (Cucurbitaceae, Cucurbiteae). Grana 44: 129-136.

Campos, S.M. 1962. Pollen grains of Plants of the Cerrado- IV. Revista Brasileira de Biologia 22: 307-315.

Cruz-Barros, M.A.V. \& Souza L.N. 2005. Flora polínica da Reserva do Parque Estadual das Fontes do Ipiranga (São Paulo, Brasil). Família: 10-Piperaceae. Hoehnea 32: 77-85.

Erdtman, G. 1952. Pollen morphology and plant taxonomyAngiosperms. Almqvist \& Wicksell, Stockholm.
Erdtman, G. 1960. The acetolysis method. A revised description. Svensk Botanisk Tidskrift 54: 61-564.

García, D.L.Q., Hernandéz, C.L., \& Sanchéz, M.L.A. 2003. Morfología de los granos de pólen de la família Cucurbitaceae del Estado de Queretáro, México. Polibotánica 16: 29-48.

Klein, V.L.G. 2001. Flora Fanerogâmica da Reserva do Parque Estadual das Fontes do Ipiranga (São Paulo, Brasil). Família: 61-Cucurbitaceae. Hoehnea 28: 5-13.

Lira, R. 2004. El género Sicydium (Cucurbitaceae, Zanonioideae, Zanonieae, Sicydiinae) en México. Acta Botanica Mexicana 68: 39-64.

Lira, R., Alvarado, J.L. \& Ayala-Nieto, M.L. 1998. Pollen morphology in Sicydium (Cucurbitaceae, Zanonioideae). Grana 37: 215-221. 
Melhem, T.S. 1966. Pollen grains of the "Cerrado". XII Cucurbitaceae, Menispermaceae and Moraceae. Anais da Academia Brasileira de Ciências 38: 195-203.

Melhem, T.S., Giulietti, A.M., Forero, E., Barroso, G.M., Silvestre, M.S.F., Jung, S.L., Makino, H., Melo, M.M.R.F., Chiea, S.C., Wanderley, M.G.L., Kirizawa, M. \& Muniz, C. 1981. Planejamento para a elaboração da "Flora Fanerogâmica da Reserva do Parque Estadual das Fontes do Ipiranga (São Paulo, Brasil)". Hoehnea 9: 63-74.

Melhem, T.S., Makino, H., Silvestre, M.S.F., Cruz, M.A.V. \& Jung-Mendaçolli, S. 1984. Planejamento para a elaboração da "Flora Polínica da Reserva do Parque Estadual das Fontes do Ipiranga (São Paulo, Brasil)". Hoehnea 11: 1-7.

Melhem, T.S., Cruz-Barros, M.A.V., Corrêa, A.M.S., Makino-Watanabe, H., Silvestre-Capelato, M.S.F. \& Esteves, V.L.G. 2003. Variabilidade polínica em plantas de Campos do Jordão (São Paulo, Brasil). Boletim do Instituto de Botânica 16: 1-104.
Nakajima, J.N., Esteves, R.L., Gonçalves-Esteves, V., Magenta, M.A.G., Bianchini, R.S., Pruski, J.F. \& Hind, D.J.N. 2001. Flora Fanerogâmica da Reserva do Parque Estadual das Fontes do Ipiranga (São Paulo, Brasil). 159-Asteraceae. Hoehnea 28: 111-181.

Perveen, A. \& Qaiser, M. 2008. Pollen flora of Pakistan -LVI- Cucurbitaceae. Pakistan Journal of Botany 40: 9-16.

Punt, W., Hoen, P.P., Blackmore, S., Nilsson, S. \& Le Thomas, A. 2007. Glossary of pollen and spore terminology. Review of Palynology and Palynology143: $1-81$.

Roubik, D.W. \& Moreno P., J.E. 1991. Pollen and spores of Barro Colorado Island. Monographs in Systematic Botany 36: 1-268.

Schaefer, H. \& Renner S.S. 2011. Phylogenetic relationships in the order Cucubitales and a new classification of the gourd family (Cucurbitaceae). Taxon 60: 122-138.

Van der Ham, R. \& Pruesapan, K. 2006. Pollen morphology of Zehneria s.l. (Cucurbitaceae). Grana 45: 241-248. 